\title{
RESEARCH
}

Open Access

\section{Metformin mediates neuroprotection and attenuates hearing loss in experimental pneumococcal meningitis}

\author{
Lukas Muri ${ }^{1,2+}$, Ngoc Dung Le ${ }^{1,2+}$, Jonas Zemp ${ }^{1}$, Denis Grandgirard ${ }^{1}$ and Stephen L. Leib ${ }^{1 *}$ (D)
}

\begin{abstract}
Background: Pneumococcal meningitis is associated with high risk of neurological sequelae such as cognitive impairment and hearing loss. These sequelae are due to parenchymal brain and inner ear damage primarily induced by the excessive inflammatory reaction in response to bacterial brain invasion. Metformin - a biguanide drug to treat diabetes mellitus type 2-was recently found to suppress neuroinflammation and induce neuroregeneration. This study evaluated the effect of metformin adjunctive to antibiotics on neuroinflammation, brain and inner ear damage, and neurofunctional outcome in experimental pediatric pneumococcal meningitis.
\end{abstract}

Methods: Eleven-day-old Wistar rats were infected intracisternally with $5.22 \pm 1.27 \times 10^{3}$ CFU Streptococcus pneumoniae and randomized for treatment with metformin $(50 \mathrm{mg} / \mathrm{kg}$, i.p., once daily for 3 weeks) plus ceftriaxone (100 mg/kg, i.p., bid, $n=61$ ) or ceftriaxone monotherapy $(n=79)$. Cortical damage and hippocampal apoptosis were evaluated histomorphometrically $42 \mathrm{~h}$ post infection. Cerebrospinal fluid cytokine levels were analyzed during acute infection. Five weeks post infection, auditory brainstem responses were measured to determine hearing thresholds. Spiral ganglion neuron density and abundance of recently proliferated and integrated hippocampal granule neurons were assessed histologically. Additionally, the anti-inflammatory effect of metformin was studied in primary rat astroglial cells in vitro.

Results: Upon pneumococcal infection, metformin treatment significantly reduced levels of inflammatory cytokines and nitric oxide production in cerebrospinal fluid and in astroglial cell cultures in vitro $(p<0.05)$. Compared to animals receiving ceftriaxone monotherapy, adjunctive metformin significantly reduced cortical necrosis $(p<0.02)$ during acute infection and improved median click-induced hearing thresholds (60 dB vs. $100 \mathrm{~dB}, p<0.002) 5$ weeks after infection. Adjuvant metformin significantly improved pure tone hearing thresholds at all assessed frequencies compared to ceftriaxone monotherapy $(p<0.05)$ and protected from PM-induced spiral ganglion neuron loss in the inner ear $(p<0.05)$.

Conclusion: Adjuvant metformin reduces brain injury during pneumococcal meningitis by decreasing the excessive neuroinflammatory response. Furthermore, it protects spiral ganglion neurons in the inner ear and improves hearing impairments after experimental pneumococcal meningitis. These results identify adjuvant metformin as a promising therapeutic option to improve the outcome after pediatric pneumococcal meningitis.

Keywords: Pneumococcal meningitis, Brain injury, Neuroinflammation, Neurologic sequelae, Metformin, Inner ear damage, Neuroregeneration

\footnotetext{
* Correspondence: stephen.leib@ifik.unibe.ch

${ }^{\dagger}$ Lukas Muri and Ngoc Dung Le contributed equally to this work.

${ }^{1}$ Neuroinfection Laboratory, Institute for Infectious Diseases, University of

Bern, Friedbühlstrasse 51, 3010 Bern, Switzerland

Full list of author information is available at the end of the article
}

(c) The Author(s). 2019 Open Access This article is distributed under the terms of the Creative Commons Attribution 4.0 International License (http://creativecommons.org/licenses/by/4.0/), which permits unrestricted use, distribution, and

reproduction in any medium, provided you give appropriate credit to the original author(s) and the source, provide a link to the Creative Commons license, and indicate if changes were made. The Creative Commons Public Domain Dedication waiver (http://creativecommons.org/publicdomain/zero/1.0/) applies to the data made available in this article, unless otherwise stated. 


\section{Introduction}

Streptococcus pneumoniae and Neisseria meningitidis are the most prevalent pathogens of childhood meningitis beyond neonatal age [1, 2]. Pneumococcal meningitis (PM) is associated with a high risk for neurologic disabilities, as one-third of PM survivors present with neurofunctional sequelae including hearing loss, epilepsy, cerebral palsy, cognitive impairment, and learning disability [3-5]. Pneumococci are reported to reach the brain through the bloodstream after successful nasopharyngeal colonization with subsequent bloodstream invasion and survival $[4,6]$. Bacteria are proposed to transmigrate through the blood-brain barrier (BBB) by receptor-mediated endothelial adhesion and transcytosis using an interplay between the platelet-activated factor receptor (PAFr), polymeric Ig receptor (pIgR), and platelet endothelial adhesion molecule (PECAM-1) expressed on the host's endothelial cells [6-11]. Notably, pneumococci might also gain access to the CNS through a paracellular route by disrupting the BBB's integrity via pneumolysinand $\alpha$-glycerophosphate oxidase (GlpO)-induced damage to endothelial cells [12-14]. In addition, pneumococcal CNS infections may arise after local spreading of bacteria from nearby focal infections (i.e., otitis media, sinusitis, or mastoiditis). Upon recognition of the invading pathogens, recruited neutrophils together with brain-resident immune cells produce high levels of inflammatory cytokines, reactive oxygen and nitrogen species (ROS and RNS), intended to eliminate the invading pathogens but also causing collateral damage to the vulnerable brain tissue $[4,15,16]$. This excessive neuroinflammatory response upon pneumococcal cerebrospinal fluid (CSF) invasion together with pneumococcal toxins contributes to PM-associated central and peripheral nervous system (CNS and PNS) injury [4, 17-20]. A hallmark of PM is the intense neutrophilic pleocytosis in the CSF in reaction to invading bacteria [21-23]. PM-induced brain injury is characterized by cortical necrosis-as a consequence of ischemia and hypoxia by a combination of reduction blood perfusion of the brain with focal cerebral vasculitis and vasospasms [24, 25]. Apoptosis in the hippocampal dentate gyrus involving granular cell progenitors [26-29] — which has been linked to learning and memory impairment in independent experimental models [30-32] - represents a second form of neuronal damage upon PM. Furthermore, spreading pneumococci and leukocytes from the CSF to the perilymphatic space of the cochlea result in damage of cochlear sensory hair cells and spiral ganglion neurons (SGNs) in the inner ear $[5,33-35]$, being responsible for hearing loss in up to $30 \%$ of surviving patients $[3,36,37]$.
Corticosteroids are recommended as adjuvant therapy to downmodulate the detrimental inflammation during PM [38, 39]. In a comprehensive meta-analysis, dexamethasone was shown to improve the outcome of adults with PM and children with meningitis caused by Haemophilus influenzae type $\mathrm{b}$-without showing a beneficial effect in pediatric PM [38]. In experimental pediatric $\mathrm{PM}$, dexamethasone even aggravates hippocampal regeneration and learning deficiency [32, 40]. Therefore, it is important to find alternative therapeutic approaches to alleviate the diseases burden in children suffering from PM.

Metformin is a biguanide drug widely used for the treatment of patients with type 2 diabetes since the 1960s. It enhances insulin sensitivity, induces glycolysis, and suppresses gluconeogenesis in the liver [41]. Metformin activates the adenosine monophosphate-activated protein kinase (AMPK) in hepatocytes, resulting in the downregulation of the expression of genes involved in hepatic gluconeogenesis [42]. Important in the framework of brain inflammation is the finding that AMPK activation suppresses the expression of pro-inflammatory cytokines in lipopolysaccharide (LPS)-injected rats [43]. In experimental multiple sclerosis, metformin significantly reduced neuroinflammation in vitro and in vivo [44]. Metformin reduced neuroinflammation and hippocampal cell death in diabetic mice, with subsequent improved performance in spatial memory tests [45] and was shown to be neuroprotective in experimental Parkinson's disease [46]. Furthermore, metformin protected CA1 pyramidal cell of the hippocampus from ischemia/reperfusion injury [47] and protected cochlear hair cells from gentamicin-induced toxicity [48]. In addition to its neuroprotective effects, metformin has recently been shown to potently promote neurogenesis in the hippocampus and cortex by enhancing neural precursor self-renewal, proliferation, and differentiation [42, 49]. Increased neurogenesis upon metformin treatment resulted in improved memory formation in multiple experimental models of brain injury [47, 50-53].

We therefore hypothesize that adjuvant metformin during acute PM reduces the excessive neuroinflammation and subsequent brain and cochlear injury-hallmarks of poor prognosis in PM. In addition, chronic metformin application may support neuroregeneration, thereby improving neurofunctional outcomes after PM.

\section{Methods}

\section{Infecting organism}

A clinical isolate of Streptococcus pneumoniae (serotype 3) from a patient with bacterial meningitis was cultured overnight in brain heart infusion (BHI) medium, diluted tenfold in fresh, pre-warmed BHI medium and grown for $5 \mathrm{~h}$ to reach the logarithmic growth phase. The 
bacteria were centrifuged for $10 \mathrm{~min}$ at $3100 \times g$ at $4{ }^{\circ} \mathrm{C}$, washed twice, resuspended in saline $(\mathrm{NaCl} 0.85 \%)$, and further diluted in saline to the desired optical density $\left(\mathrm{OD}_{570 \mathrm{~nm}}\right)$. The inoculum concentration was determined by serial dilution and culturing on Columbia sheep blood agar (CSBA) plates. Bacterial preparation for $S$. pneumoniae D39 wild type (serotype 2) and its non-encapsulated mutant R6 were performed as described above with minor adaptions. Overnight cultivation was shortened to $8 \mathrm{~h}$ and time for logarithmic growth was reduced to $1.5 \mathrm{~h}$ for D39.

\section{In vitro astroglial cells stimulation}

Astroglial cells consisting of astrocytes, microglia, and oligodendrocytes were isolated from infant rat brains at postnatal day 3 (P3), as previously reported [54]. Briefly, rats were sacrificed by decapitation and brains were isolated. The cortices were homogenized mechanically in PBS by pipetting up and down with a $5 \mathrm{ml}$ plastic pipette, centrifuged $\left(500 \times g, 7 \mathrm{~min}, 4{ }^{\circ} \mathrm{C}\right)$ and resuspended in DMEM (Sigma-Aldrich, Merck Switzerland) containing 5\% FCS (Biochrom, Germany), GlutaMAX ${ }^{\mathrm{Tn}}$ (ThermoFisher, Switzerland), and antibiotic-antimycotic solution (ThermoFisher, Switzerland). After resuspension, cells were plated in T75 flask (TPP ${ }^{\circ}$, Merck) previously coated with poly-L-ornithine (PLO, $0.01 \mathrm{mg} / \mathrm{ml}$ in PBS, Sigma-Aldrich). On day 11 post isolation, cells were seeded on PLO-coated 24-well plates, at a density of 200,000 cells/well. Astroglial cells were stimulated with (a) $10 \mu \mathrm{g} / \mathrm{ml}$ lipopolysaccharide (from Escherichia coli, L2654, Sigma-Aldrich) in PBS, (b) heat-inactivated $S$. pneumoniae serotype $3\left(3 \times 10^{7} \mathrm{CFU} / \mathrm{ml}\right)$, or (c) living $S$. pneumoniae serotype $3\left(2 \times 10^{7} \mathrm{CFU} / \mathrm{ml}\right)$ treated with ceftriaxone (CRO, $12 \mathrm{mg} / \mathrm{ml}$, Rocephine, Roche). For each stimulus, cells treated with metformin (metformin hydrochloride, $10 \mathrm{mM}$, Sigma-Aldrich) were compared to vehicle-treated cells. Heat-inactivation of S. pneumoniae serotype 3 was performed in a thermo-shaker (Thermomixer comfort, Vaudaux-Eppendorf AG, Switzerland) at $56{ }^{\circ} \mathrm{C}$ for $30 \mathrm{~min}$. To confirm serotypeindependent anti-inflammatory properties of metformin, its effect was further assessed on astroglial cells stimulated with living D39 $\left(6 \times 10^{7} \mathrm{CFU} / \mathrm{ml}\right)$ or $\mathrm{R} 6\left(7 \times 10^{7}\right.$ $\mathrm{CFU} / \mathrm{ml}$ ) treated with ceftriaxone. The use of ceftriaxone after stimulation with living bacteria is required to guarantee astroglial cell survival. Additionally, it mimics the in vivo model with antibiotic-induced bacteriolysis, which initially increases the neuroinflammatory reaction upon antibiotic treatment initiation.

\section{Quantification of nitric oxide production in vitro}

After $24 \mathrm{~h}$ of astroglial cell stimulation, $100 \mu \mathrm{l}$ of the cell culture supernatant from each well was collected and centrifuged $\left(13,000 \mathrm{rpm}, 5 \mathrm{~min}, 4{ }^{\circ} \mathrm{C}\right)$, transferred to a 96-well plate, followed by addition of $100 \mu \mathrm{l}$ Griess reagent (Sigma-Aldrich). $\mathrm{NO}_{2}{ }^{-}$content was determined by measuring the absorbance at $550 \mathrm{~nm}$ with a microplate reader (Molecular Devices, THERMO max). A serial dilution of $\mathrm{NaNO}_{2}$ solution (Sigma-Aldrich) from 100 to $1.5625 \mu \mathrm{M}$ was measured and used to create a standard curve for quantification. $\mathrm{NO}_{2}{ }^{-}$concentration in cell culture supernatant served as a proxy for $\mathrm{NO}$ release, and is further addressed as NO.

\section{Infant rat model of pneumococcal meningitis}

All animal studies were approved by the Animal Care and Experimentation Committee of the Canton of Bern, Switzerland (license no. BE 129/14 and 01/18). A wellestablished infant rat model of pneumococcal meningitis was used for this study [35, 55]. Eleven-day-old female and male Wistar rat pups and their dams were purchased from Charles Rivers (Sulzfeld, Germany). The dams were provided with tap water and pellet diet ad libitum. Litters were kept in rooms at a controlled temperature of $22 \pm 2{ }^{\circ} \mathrm{C}$. During the acute phase of the disease (from infection to $42 \mathrm{~h}$ after infection), animals were housed in a room with natural light. For the longterm experiments, the animals were transferred to individually ventilated cages (IVC) in a room with controlled $12 \mathrm{~h}$ light/dark cycles. The pups were infected intracisternally with $10 \mu \mathrm{l}$ of the inoculum containing $5.22 \pm$ $1.27 \times 10^{5} \mathrm{CFU} / \mathrm{ml}$ of living S. pneumonia serotype 3 . Control animals were injected with $10 \mu \mathrm{l}$ saline. Meningitis was confirmed by quantitative analysis of bacterial titers in the cerebrospinal fluid (CSF) at $18 \mathrm{hpi}$, where $5 \mu \mathrm{l}$ of CSF were collected by puncture of the cisterna magna, followed by serial dilution and cultivation on CSBA plates.

A total of 174 infant were included in this study, representing 17 independent experiments with 7,12 , or 14 infant rats per experiment. Seventy-six animals were investigated during acute PM to assess neuroinflammation and brain damage, and 98 animals were studied to investigate neurofunctional outcomes. Infected and mock-infected animals were randomized for treatment with adjuvant metformin $(50 \mathrm{mg} / \mathrm{kg}$, i.p. $)$ and/or CRO (100 mg/kg, i.p., twice daily [b.i.d.]). Animals with CRO monotherapy received a i.p. vehicle injection. All animals received the same amount of fluids during the experiment. Both therapies were initiated at 18 hpi. For the acute experiments, clinical scoring was performed by investigators blinded to treatment modalities of individual animals. The animals were weighted and clinically scored according to the following scoring scheme $(1=$ coma, $2=$ does not turn upright, $3=$ turns upright in $>$ $5 \mathrm{~s}, 4=$ turns upright in $<5 \mathrm{~s}, 5=$ normal) at $0,18,24$, and before sacrificing at $42 \mathrm{hpi}$. Spontaneous mortality was documented. CSF samples at 18, 24, and $42 \mathrm{hpi}$ 
were obtained by puncture of the cisterna magna using a 30-gauge needle. CSF samples were centrifuged (16, $000 \times g, 10 \mathrm{~min}, 4{ }^{\circ} \mathrm{C}$ ) and supernatants were stored at $80{ }^{\circ} \mathrm{C}$ for later CSF cytokine measurements. For longterm experiments, CRO therapy was continued for the first 5 days after infection. Animals treated with metformin received chronic daily metformin application for additional 2 weeks, whereas animals from the CRO monotherapy group received daily vehicle injections. In addition, bromodeoxyuridine (BrdU, $50 \mathrm{mg} / \mathrm{kg}$, SigmaAldrich) was given once daily on day 3-5 after infection combined with CRO. Animals were sacrificed with pentobarbital (Esconarkon', $150 \mathrm{mg} / \mathrm{kg}$, i.p., Streuli Pharma AG, Switzerland) and perfused with $4 \%$ paraformaldehyde (PFA, Merck) in phosphate-buffered saline (PBS). Brains and cochleas were harvested and fixed in $4 \%$ for histological analysis.

\section{Histomorphometric analysis of cortical damage and hippocampal apoptosis}

Damage to the cerebral structures was quantified in all animals sacrificed at $42 \mathrm{hpi}$, as previously described by us and other independent research groups [56-59]. Brains were fixed in 4\% PFA and cryopreserved in $18 \%$ sucrose in $\mathrm{PBS}$ at $4{ }^{\circ} \mathrm{C}$ overnight. Brain cryosections $(45 \mu \mathrm{m})$ were systematically sampled with a cutting frequency of 15 and stained for Nissl substance with cresyl violet. Cortical damage was defined as areas of decreased neuronal density with histological features of necrosis, using ImageJ software. Dead cells with histological features of apoptosis were quantified in 48 visual fields spanning the hippocampal dentate gyrus by using $\times 400$ magnification. Histologic assessment was performed and evaluated by investigators blinded to treatment modalities of the individual animals.

\section{Analysis of cytokine expression in CSF}

Cytokines known to be upregulated during PM (IL-1 $\beta$, IL-6, TNF- $\alpha$, IL-10, and IFN- $\gamma$ ) were assessed using magnetic multiplex assay (Rat Magnetic Luminex ${ }^{\oplus}$ Assay, Rat Premixed Multi-Analyte Kit, R\&D Systems, BioTechne) on a Bio-Plex 200 station (Bio-Rad Laboratories) as described previously [35, 60]. Five microliter of CSF harvested at 18, 24, and $42 \mathrm{hpi}$ were diluted to a final volume of $50 \mu \mathrm{l}$. For in vitro samples, $50 \mu \mathrm{l}$ of cell culture medium was used undiluted. For each sample, a minimum of 50 beads was measured. If the concentration of the sample was below the detection limit, a value corresponding to the detection limit provided by the manufacturer was used, considering the dilution factor. The detection limits for undiluted samples were $2.93 \mathrm{pg} /$ $\mathrm{ml}$ for IL-1 $\beta, 23.2 \mathrm{pg} / \mathrm{ml}$ for IL-6, $8.95 \mathrm{pg} / \mathrm{ml}$ for IL-10, $11.5 \mathrm{pg} / \mathrm{ml}$ for TNF- $\alpha$, and $70.9 \mathrm{pg} / \mathrm{ml}$ for IFN- $\gamma$.

\section{Assessment of hearing capacity by measuring auditory brainstem response}

Five weeks post infection, auditory brainstem responses (ABR) were performed to determine the hearing thresholds of the animals, as described previously [35, 60]. Click and pure tone recordings were performed with the Intelligent Hearing Systems SmartEP system. Animals were anesthetized with $5 \%$ isoflurane (Attane TM, Piramal healthcare). The anesthetized animal was placed on a heating pad in a soundproof chamber. A rubber facial mask was put on the animal for continuous delivery of isoflurane. As soon as the animal was under deep anesthesia, the isoflurane concentration was reduced to $2 \%$. Subdermal electrodes were placed in the mastoid of the tested ear (active), at the vertex (reference) and in the lower limb (ground). Earphones were placed in the outer auricular canal. Click stimuli and 5-ms pure tone bursts $(4,8,16$, and $32 \mathrm{kHz})$ were presented at a rate of $21.1 \mathrm{~s}^{-1}$, ranging from 100 to $20 \mathrm{~dB}$ sound pressure level (SPL) in $10 \mathrm{~dB}$ decrements $(5 \mathrm{~dB}$ decrements close to threshold). The hearing threshold was defined as the lowest intensity that induced a visually detectable first peak. Hearing thresholds were independently analyzed by investigators blinded to treatment modality.

\section{Immunohistological assessment of spiral ganglion neuron density}

Six weeks post infection, the region of the temporal bone containing the cochlea was dissected from skull, fixed in $4 \%$ PFA, and then transferred to OsteoSoft ${ }^{\circ}$ (Merck) for 7-10 days. OsteoSoft was replaced by 30\% sucrose in PBS $24 \mathrm{~h}$ before cutting. Left cochleas were used for the spiral ganglion histology, whereas the right ones were kept as back-up. Then, $14 \mu \mathrm{m}$ sections were cut and mounted on Superfrost Plus Menzel glass slides. The staining procedure was performed with a Shandon Sequenza staining rack (Thermo Fisher Scientific). Sections were permeabilized for $5 \mathrm{~min}$ with $0.1 \%$ Triton-X, followed by blocking with blocking solution (PBS with $2 \%$ BSA and $0.01 \%$ Triton-X) for $1 \mathrm{~h}$ at room temperature (RT). The primary antibody BIII-tubulin (1: 500, mouse-anti-rat, Promega G712A) was diluted in blocking solution and incubated overnight at $4{ }^{\circ} \mathrm{C}$. The sections were rinsed with $3 \times 500 \mu \mathrm{l}$ PBS and incubated with the secondary antibody (goat-anti-mouse Alexa Fluor 488, 1:500, Thermo Fisher Scientific, A-11029) for $2 \mathrm{~h}$ at RT. After rinsing again, the slides were mounted with Fluoroshield ${ }^{\mathrm{Tm}}$ with DAPI (Sigma-Aldrich). Images of the spiral ganglions were acquired using a fluorescent microscope (ZEISS Axio, Imager M1, West Germany) equipped with a digital camera (Zeiss AxioCam HRc). 
Immunohistological assessment of $\mathrm{BrdU}^{+}$and $\mathrm{NeuN}^{+}$cells in the hippocampal dentate gyrus

Brains were harvested 6 weeks post infection and fixed in $4 \%$ PFA for $4 \mathrm{~h}$ and stored in PBS at $4{ }^{\circ} \mathrm{C}$ for later embedding in paraffin. Ten micrometer sections were cut using a microtome (Microm, Germany). Every 18th section was sampled on Superfrost Plus Menzel glass slides and air dried. Sections were deparaffinized and submitted to antigen retrieval by incubating the slides in sodium citrate (Merck KGaA) $10 \mathrm{mM}$ pH 6.0 for $1 \mathrm{~h}$ in a $95{ }^{\circ} \mathrm{C}$ water bath. The brain sections were permeabilized and blocked as described above. The primary antibodies BrdU (1:500, sheep-anti-rat, abcam, ab1893) and NeuN (1:500, mouse-anti-rat, Millipore, MAB377) were diluted in blocking solution, added to the slides and incubated overnight at $4{ }^{\circ} \mathrm{C}$. The slides were washed $3 \times 5$ min with PBS and the secondary antibodies-donkey-anti-sheep Alexa Fluor 488 (1:500, Thermo Fisher Scientific, A11015) and donkey-anti-mouse Cy3 (1:500, Jackson ImmunoResearch, 715-165-151)-were added for $2 \mathrm{~h}$ at RT. After washing the sections $3 \times 5 \mathrm{~min}$ in PBS, they were mounted with Fluoroshield containing DAPI and kept at $4{ }^{\circ} \mathrm{C}$ in dark until imaging. $\mathrm{BrdU}^{+}$cells in the $\mathrm{NeuN}^{+}$region of the dentate gyrus were quantified using a $\times 400$ magnification on fluorescent microscope. The first six sampled sections containing the dentate gyrus with the upper and lower blades connected were quantified. A mosaic picture of each dentate gyrus was created with Zeiss AxioVision software using individual pictures taken with the DAPI fluorescence channel at $\times 100$ magnification. The mosaic was used for determining the area of the dentate gyrus with ImageJ software. Number of $\mathrm{BrdU}^{+}$cells were then calculated and evaluated as number of $\mathrm{BrdU}^{+}$cells per $\mathrm{mm}^{2}$ dentate gyrus granule cell layer.

\section{Statistical analysis}

Statistical analyses were performed with GraphPad Prism (Prism 7; GraphPad Software Inc., San Diego, USA). Results are presented as mean values \pm standard deviation if not stated otherwise. Survival was calculated using a log rank (Mantel-Cox) test. To compare differences between means of two normally distributed groups, an unpaired Student $t$ test or Welch's $t$ test were used (cortical damage assessed with Welch's $t$ test). To assess differences between non-normal distributed data (hearing thresholds, hippocampal apoptosis), a nonparametric Mann-Whitney test was used. A two-way ANOVA was performed to analyze differences between treatment modalities and to pure-tone hearing frequencies. Repeated-measure ANOVA was used to assess differences in spiral ganglion neuron density from the three cochlear regions (base, middle, apex). Repeatedmeasure ANOVAs were executed on STATA 12 (STATA
Corp., College Station, TX). A $p$ value of $<0.05$ was considered statistically significant with $p<0.05\left(^{*}\right), p<0.01$ ${ }^{(* *)}, p<0.001{ }^{(* * *)}$ ), and $p<0.0001{ }^{(* * * * *)}$.

\section{Results}

Adjuvant metformin reduces inflammatory cytokine levels and nitric oxide production in vitro

Primary astroglial cell cultures from infant rats were stimulated with LPS, heat-inactivated (HI P21), or living S. pneumoniae serotype 3 (living P21) and treated with metformin. All three stimuli potently activated astroglial cells in vitro as determined by increased levels of inflammatory cytokines and $\mathrm{NO}$ in the cell culture medium (Fig. 1a-f). In LPS-stimulated cells, metformin significantly reduced the release of IL- $1 \beta$ $(p=0.0109)$, IL-6 $(p=0.0050)$, and NO $(p=0.0024)$ and showed trends toward reduced levels of IL-10 $(p=0.069)$ and TNF- $\alpha \quad(p=0.056)$. Metformin also drastically reduced the release of IL-1 $\beta \quad(p=0.0004)$, IL-6 $\quad(p=0.0003), \quad$ IL-10 $\quad(p=0.0015), \quad$ TNF- $\alpha \quad(p<$ $0.0001)$, and NO $(p=0.0003)$ induced by HI P21 stimulation. After exposure to living bacteria, adjuvant metformin to ceftriaxone treatment attenuated the levels of IL-6 $(p=0.0229)$ and NO $(p=0.0005)$, without significantly affecting the other measured cytokines. Of note, levels of IL-1 $\beta$ and TNF- $\alpha$ were considerably higher in astroglial cells exposed to living bacteria compared to HI P21 and LPS. Additionally, in contrast to the clear release of IL-10 in HI P21 and living P21 stimulated cells, LPS only marginally induced IL-10 production (Fig. 1c). In non-stimulated control cells, the production of cytokines and $\mathrm{NO}$ was at very low levels (IL- $1 \beta<10 \mathrm{pg} / \mathrm{ml}$; IL- $6<$ $105 \mathrm{pg} / \mathrm{ml} ; \mathrm{IL}-10<35 \mathrm{pg} / \mathrm{ml} ;$ TNF- $\alpha<65 \mathrm{pg} / \mathrm{ml} ;$ IFN$\gamma<85 \mathrm{pg} / \mathrm{ml} ; \mathrm{NO}<0.5 \mu \mathrm{M}$, data not shown). The anti-inflammatory effect of metformin was further confirmed to be independent of serotype-specific surface polysaccharides, as metformin treatment also significantly reduced the release of IL- $1 \beta$, IL- 6 , TNF- $\alpha$, and NO after stimulation of astroglial cells with $S$. pneumoniae serotype 2 (D39, see Additional file 1). These anti-inflammatory properties were further documented to be capsule-independent as metformin significantly reduced the release of IL- $1 \beta$, IL- 6 , TNF- $\alpha$, and NO to a similar extent after astroglial cell stimulation with R6-a non-encapsulated mutant of D39 (see Additional file 1).

\section{Adjuvant metformin does not affect clinical parameters during acute PM}

Overall, 174 infant Wistar rats were included in the study. All animals infected with $S$. pneumoniae serotype $3(n=140)$ developed meningitis, which was proven by growth of bacteria $\left(\geq 10^{6} \mathrm{CFU} / \mathrm{ml}\right)$ in CSF samples 

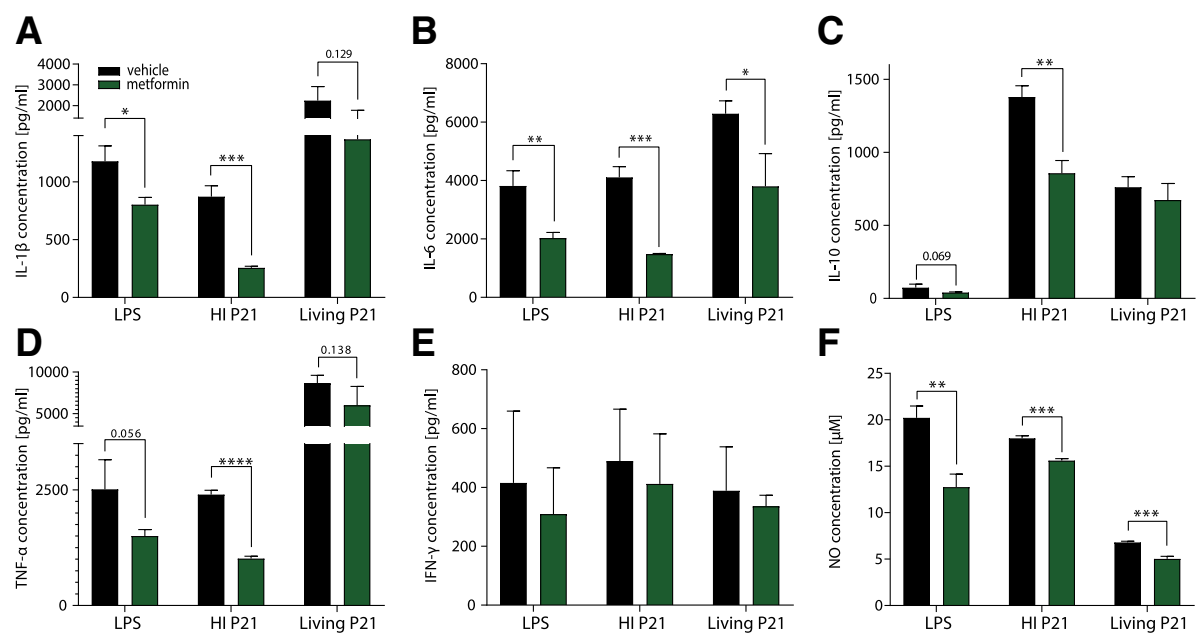

Fig. 1 Reduced levels of inflammatory cytokines and NO after stimulation of astroglial cells in vitro. Primary neonatal rat astroglial cells were either stimulated with LPS, heat-inactivated (HI P21), or living S. pneumoniae serotype 3 (Living P21) in the presence or absence of metformin. Metformin significantly reduced levels of IL-1 $\beta$ ( $p=0.0109$ in LPS- and $p=0.0004$ in HI P21 stimulated cells, a). IL-6 ( $p=0.0050$ in LPS-, $p=0.0003$ in HI P21- and $p=0.0229$ in living P21-stimulated cells, b) and nitric oxide ( $p=0.0024$ in LPS-, $p=0.0003$ in HIP21- and $p=0.0005$ in living P21stimualted cells, $\mathbf{f})$ levels were significantly reduced by metformin independent of stimulating agents. IL-10 ( $p=0.0015, \mathbf{c})$ and TNF-a ( $p<0.0001$, d) levels were significantly reduced in astroglial cells stimulated by HI P21 in the presence of metformin. No effect of metformin treatment on IFN- $\gamma$ levels (e) was found

obtained at 18 hpi and the appearance of meningitis symptoms reflected by clinical score $<5$, weight loss, and changes in posture. Sixty-one infected infant rats were treated with adjuvant metformin $(50 \mathrm{mg} / \mathrm{kg})$ in addition to CRO, and 79 infected rats received CRO monotherapy. The slightly lower number of animals receiving metformin is explained by an initially performed dose-finding study evaluating different metformin concentrations, whereupon all animals receiving a metformin dose different from $50 \mathrm{mg} / \mathrm{kg}$ were excluded from subsequent analysis.

Survival was significantly reduced in infected animals $(\mathrm{PM}+)$ compared to mock-infected animals (PM-). Adjuvant metformin treatment did not affect survival in neither infected nor non-infected animals compared to animals treated with CRO monotherapy (Fig. 2a).
Relative weight change showed a significant difference between infected and mock-infected animals during acute infection. In both infection groups, however, relative weight change was not altered by adjuvant metformin treatment neither during acute phase nor by chronic application (Fig. 2b, c).

\section{Adjuvant metformin therapy reduces levels of inflammatory cytokine in CSF and cortical necrosis but not hippocampal apoptosis}

Inflammatory cytokines were measured before treatment initiation and at $6 \mathrm{~h}$ and $24 \mathrm{~h}$ after therapy start, representing 18, 24, and 42 hpi. Immediately before treatment initiation with $\mathrm{CRO} \pm$ metformin at $18 \mathrm{hpi}$, infected animals from both groups-adjunctive metformin and CRO monotherapy-showed comparable levels of CSF
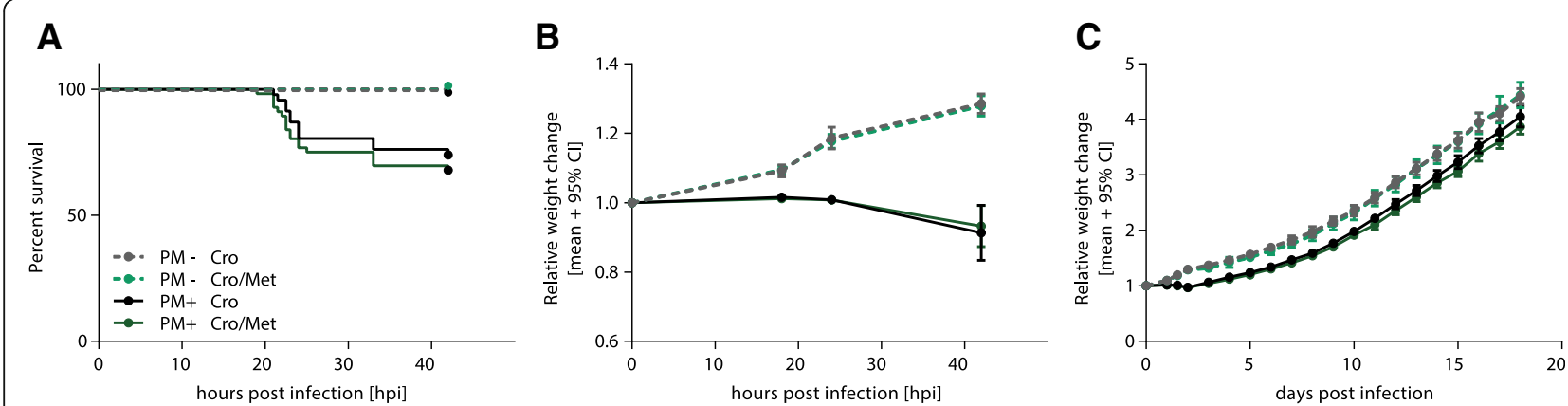

Fig. 2 Survival and weight change in infant rats with pneumococcal meningitis. Infected rats showed significantly reduced survival compared to mock-infected animals, independent of treatment regimen (a). Weight change during acute meningitis (b) and long-term recovery (c) was significantly affected by infection but not by adjuvant metformin therapy 
cytokines and bacterial CSF titers, representing a comparable degree of infection and neuroinflammation at time of treatment initiation (Fig. 3a-e). Six hours after treatment initiation, adjuvant metformin therapy significantly reduced CSF levels of the inflammatory cytokines IL-1 $\beta$ ( $p=0.015$ and $p=0.034$ at $24 \mathrm{~h}$ after treatment initiation), IL-6 $(p=0.036)$, and TNF- $\alpha(p=0.044)$. No significant difference was found for IFN- $\gamma$ and IL-10, although IL-10 showed a trend toward reduction ( $p=$ 0.059, Fig. 3c).

No cortical damage was found in mock-infected animals. Infected animals treated with adjuvant metformin had significantly reduced cortical necrosis compared to infected animals receiving CRO monotherapy (mean of damaged cortex volume $0.76 \% \pm 0.47, n=16$, vs. $3.34 \% \pm$ 0.83 in CRO monotherapy, $n=32, p=0.0101$, Fig. 3f). Apoptotic cells were found in the subgranular zone of the hippocampal dentate gyrus. Hippocampal apoptosis was found at physiological levels in mock-infected animals. Adjuvant metformin treatment did not significantly affect hippocampal apoptosis in infected animals (see Additional file 2).

\section{Metformin treatment reduces PM-induced hearing loss and protects spiral ganglion neurons}

Five weeks after infection, hearing thresholds were determined by recording response to click stimulations and pure tones on both ears. In infected animals, metformin treatment significantly improved click-induced hearing thresholds compared to animals with CRO monotherapy (60 dB, $n=44$, in metformin therapy vs. $100 \mathrm{~dB}, n=36$ in CRO monotherapy, $p=0.0015$, Fig. 4a). Pure tone ABR showed higher thresholds for all assessed frequencies $(4,8,16$, and $32 \mathrm{kHz})$ in infected animals compared to mock-infected animals $(n=44, p \leq 0.0001$, two-way ANOVA, Fig. 4b). Infected animals receiving adjuvant metformin treatment showed significantly better pure tone hearing capacity than animals treated with ceftriaxone monotherapy $(p=0.0013$, Fig. 4b). Frequency-specific analysis revealed that at all measured frequencies, hearing capacity was significantly improved in infected animals receiving adjuvant metformin compared to CRO monotherapy $(4 \mathrm{kHz} p=$ $0.0023,8 \mathrm{kHz} p=0.0026,16 \mathrm{kHz} p=0.0029,32 \mathrm{kHz}$ $p=0.0248$, Fig. $4 \mathrm{~b})$.

The densities of spiral ganglion neurons (SGNs) were assessed by counting SGNs in the basal, middle, and apical turns of mid-modiolar cochlea sections. A significant reduction of SGNs in the basal turn was determined in infected animals treated with CRO monotherapy compared to mock-infected animals (1945 \pm 141.7, SGNs $/ \mathrm{mm}^{2}$ in CRO monotherapy animals, $n=11$ vs. $2299 \pm 63.6 \mathrm{SGNs} / \mathrm{mm}^{2}$ in mock-infected animals, $n=15, p=0.0197)$. This PM-induced neurotoxicity of SGNs was prevented by adjuvant metformin treatment with no detectable SGN loss in these animals $(2211 \pm$ 107.1 SGNs $/ \mathrm{mm}^{2}$ in animals receiving metformin, $n=$

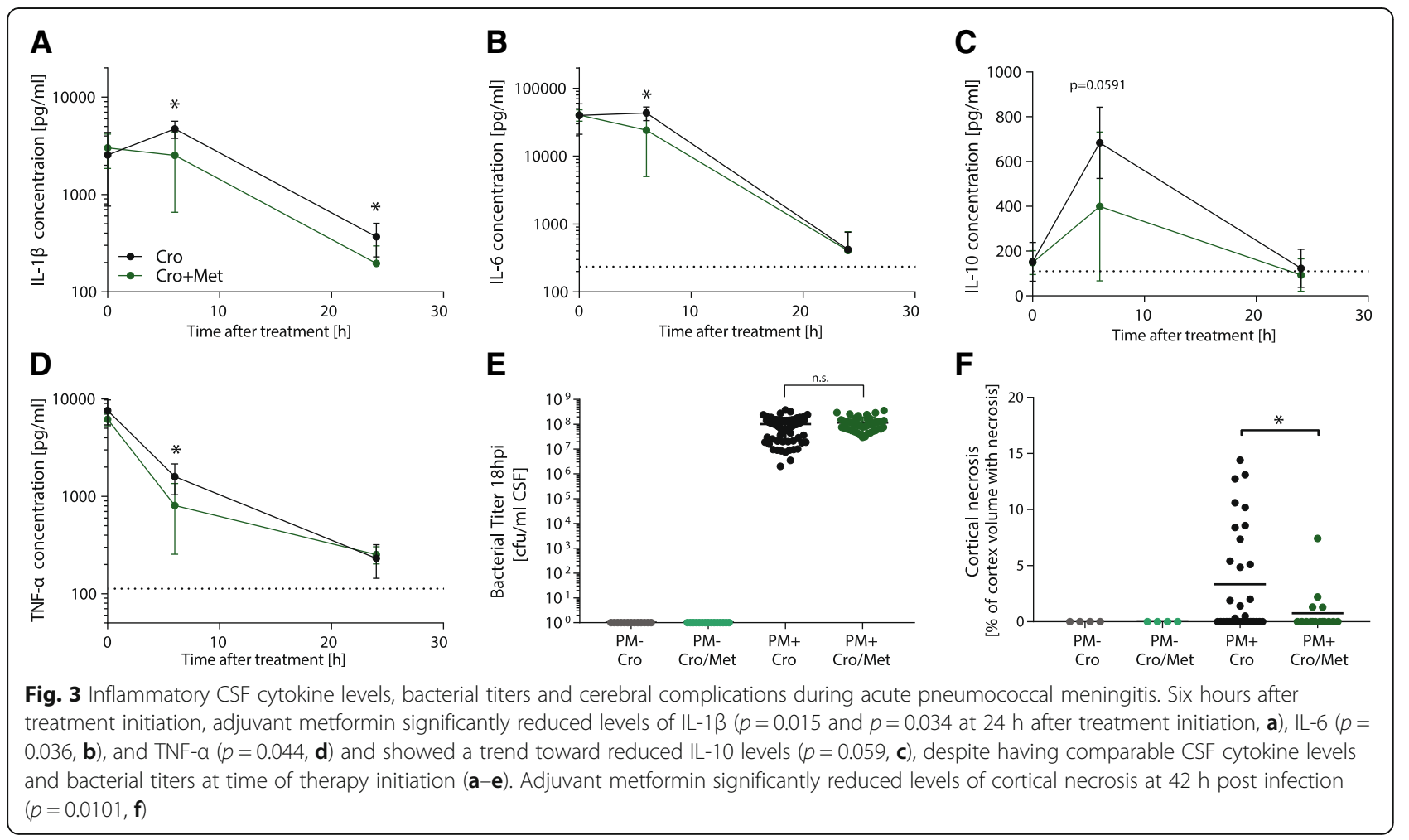




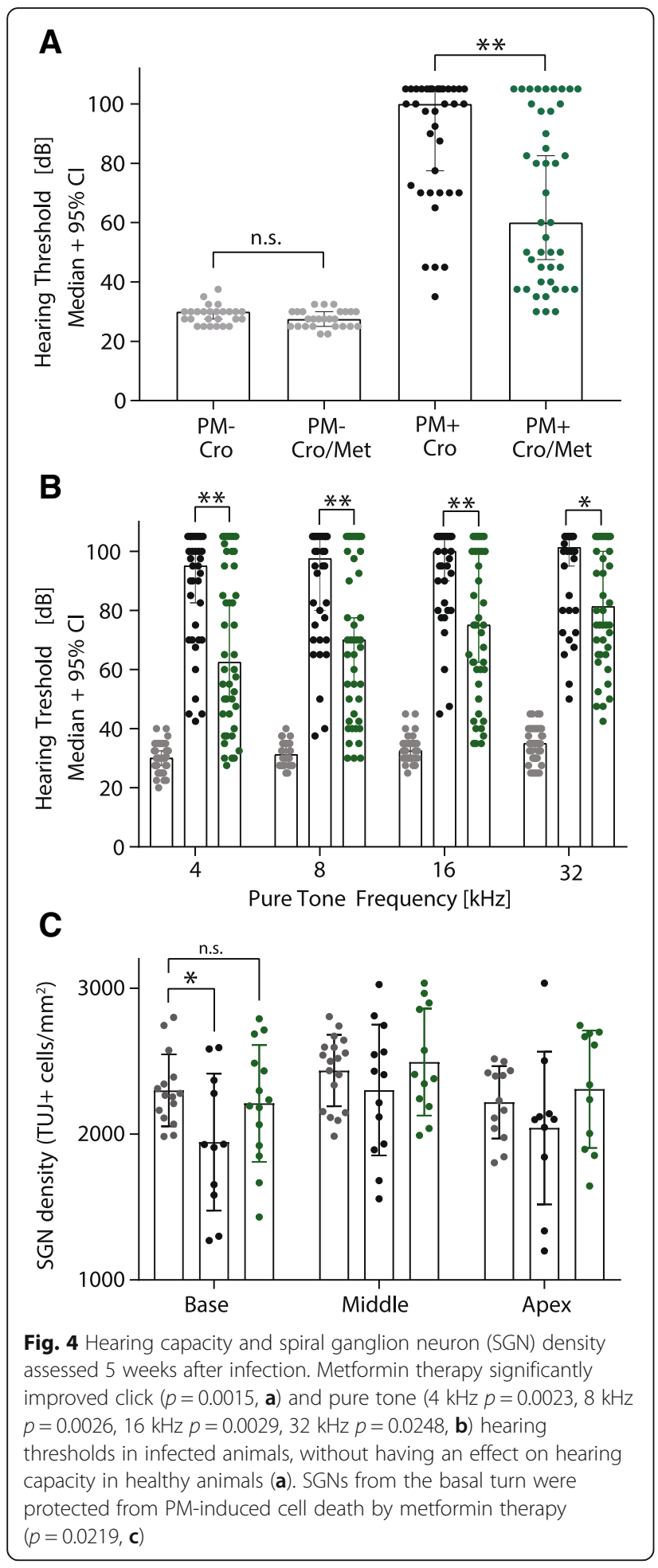

14, $p=0.475$, Fig. 4c). A repeated-measure ANOVA, which considered the different cochlear turns as repeated measurements, revealed a significant protective effect of adjuvant metformin on SGN density over all cochlear turns in infected rats compared to CRO monotherapy $(p=0.0219)$.

\section{Metformin does not promote neurogenesis in the} hippocampal neural stem cell niche

Neurogenesis was defined by cells being $\mathrm{BrdU}^{+}$and $\mathrm{NeuN}^{+}$, i.e., cells which have proliferated and incorporated BrdU after acute infection and successfully matured to neurons and integrated into existing hippocampal network 5 weeks after infection. BrdU ${ }^{+}$cells were mostly found in the subgranular zone and the granule cell layer of the dentate gyrus (DG) (Fig. 5a, b), indicating their integration into hippocampal network. $\mathrm{BrdU}^{+}$cells in the $\mathrm{NeuN}^{+}$region of the DG were quantified to assess neuronal proliferation and survival. The results revealed no significant difference between mockinfected and infected animals as well as animals which were chronically treated with metformin or their littermates which received chronic vehicle injection (Fig. 5c).

\section{Discussion}

In the present study, we investigated the anti-inflammatory, neuroprotective, and neuroregenerative effects of adjuvant metformin in PM. Our results demonstrate that treatment with adjuvant metformin in pediatric experimental PM decreases neuroinflammation, as reflected by reduced levels of inflammatory cytokines in the CSF, resulting in an attenuated cortical necrosis. These anti-inflammatory properties of metformin were further supported by results from additional in vitro experiments. Furthermore, metformin protected SGNs from PM-induced cell death and reduced PM-induced hearing loss.

Damage to the brain caused by PM is multifactorial, but mainly associated with an excessive inflammation, resulting in long-lasting neurological sequelae [5, 29, 33]. Rapid growth of $S$. pneumoniae in the subarachnoid space and released bacterial products induce a severe inflammatory response. This response may even be exacerbated after treatment with bacteriolytic antibiotics [4]. Based on these observations, adjunctive therapies are needed to attenuate the hyperinflammation in the brain during PM. Dexamethasone-an anti-inflammatory corticosteroid-is currently recommended as adjuvant therapy for adults and children with PM [38]. We have previously shown in the present model that therapy with dexamethasone showed only limited protection from PM-induced hearing loss and aggravated mortality, weight loss, and hippocampal injury with associated learning deficiency when compared to CRO monotherapy [32, 40,61]. In the present study, we specifically compared metformin therapy to CRO monotherapy but not to adjuvant dexamethasone therapy.

In vitro, primary neonatal rat astroglial cells were stimulated with LPS, heat-inactivated and living $S$. pneumoniae in the presence or absence of metformin. The anti-inflammatory effect of metformin in LPSstimulated macrophages and microglia has already 
A

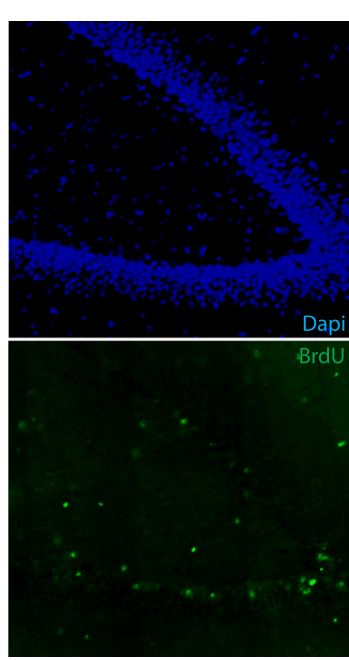

B

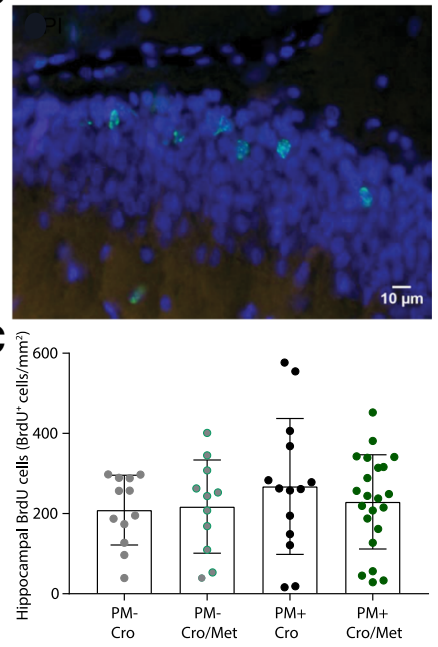

Fig. 5 Quantification of BrdU ${ }^{+}$cells in the $\mathrm{NeuN}^{+}$region of the hippocampal dentate gyrus. BrdU-positive neurons (green) are clearly visible in the granular zone of the dentate gyrus $(\mathbf{a}, \mathbf{b})$. Adjuvant metformin treatment did not promote neurogenesis neither after experimental PM nor in mock-infected animals, as no significant differences in $\mathrm{BrdU}^{+}$cell counts was detected between animals receiving metformin treatment and animals receiving $\mathrm{CRO}$ monotherapy (c)

been shown in vitro, where metformin significantly reduced the release of inflammatory cytokines and $\mathrm{NO}$ in an AMPK-dependent manner [44, 50]. The present in vitro results confirm the anti-inflammatory effects of metformin in LPS-induced neuroinflammation in primary astroglial cells. Furthermore, metformin reduced cytokines and NO levels caused by stimuli relevant for PM-induced neuroinflammation, like heat-inactivated or living pneumococci (Fig. 1a-f). We only found statistical trends for reduced IL-1 $\beta$ and TNF- $\alpha$ levels after stimulation with living P21 and treatment with metformin in vitro. However, the anti-inflammatory effect of metformin was further confirmed when stimulating the cells with living D39 and R6 with significant reduction for IL-1 $\beta$, IL-6, TNF- $\alpha$, and NO. Significant reduction of IL- $1 \beta$, IL- 6 , and TNF- $\alpha$ were also observed in the CSF of infected animals treated with metformin. As cytokines are important mediators of cerebral damage during PM, any reduction in inflammatory mediators might mediate neuroprotection in vivo [4]. The induction of most inflammatory mediators was comparable between the different stimuli, but we found notable differences such as poorly induced IL-10 levels after stimulation with LPS (Fig. 1c) or significantly higher IL-1 $\beta$ and TNF- $\alpha$ responses of cells exposed to living pneumococci (Fig. 1a, d). Lower levels of IL-1 $\beta$ and TNF- $\alpha$ in heat-inactivated pneumococci might be explained by the heat-lability of the highly immunogenic pneumolysin [13, 62]. Notably, the anti-inflammatory effect of metformin in vitro was confirmed after stimulation with a non-vaccine pneumococcal serotype (serotype 2, D39) and its non-encapsulated mutant R6, demonstrating that metformin's anti-inflammatory properties are serotype- and capsule-independent and also potently reduces inflammatory mediators after infection with a nonvaccine serotype (Additional file 1). Low and unaffected levels of IFN- $\gamma$ can be explained by the absence of $\mathrm{T}$ lymphocytes and NK cells in our cell culture, the two cell types mainly responsible to induce IFN $-\gamma$ responses [63]. Additionally, IFN- $\gamma$ serves mostly to combat intracellular pathogens [63], and only to a lesser extend against extracellular bacteria like S. pneumoniae. Comparison between the different stimuli should be interpreted with caution, since the kinetics of cytokine release may be different for each stimulus and we determined the accumulation of cytokines in the supernatant $24 \mathrm{~h}$ after stimulation.

In the in vivo study, the dose of metformin $(50 \mathrm{mg} / \mathrm{kg})$ was chosen based on preliminary pilot study and other independent studies $[43,51]$. The use of a higher metformin dose $(200 \mathrm{mg} / \mathrm{kg})$ in our pilot study resulted in significantly increased mortality and hippocampal apoptosis in infected animals treated with adjuvant metformin compared to infected animals treated with CRO monotherapy (see Additional file 2). On the other hand, $20 \mathrm{mg} / \mathrm{kg}$ metformin did not protect from PM-induced cortical damage (data not shown). Although adjuvant metformin has been reported to cause weight loss in type 2 diabetes patients [64], we did not detect significant differences in weight change between animals receiving adjuvant metformin and animals with CRO monotherapy during acute (Fig. 2b) and post-acute (Fig. 2c) phases of PM-independent of infection with $S$. pneumoniae. In addition, metformin treatment did not affect survival (Fig. 2a). Together, these data indicate that $50 \mathrm{mg} / \mathrm{kg}$ metformin during acute PM and during recovery from PM is safe as it does not affect 
mortality or weight loss. Although we found promising results using $50 \mathrm{mg} / \mathrm{kg}$ metformin as adjuvant therapy in PM, further studies are needed to identify the influence of dosing on these reported effects.

Inflammatory cytokines produced by infiltrating leukocytes and brain-resident cells are crucially involved in the pathogenesis of PM [4]. During the acute phase of $\mathrm{PM}$, levels of pro-inflammatory cytokines are drastically increased [4, 22, 55]. Metformin-dependent AMPK activation was shown to induce anti-inflammatory effects [43]. In this study, we found that adjuvant metformin significantly reduced CSF levels of inflammatory cytokines in vivo (Fig. 3) and in vitro (Fig. 1). In vivo, treatment with CRO monotherapy caused a transient increase of IL- $1 \beta$ and IL- 6 . This may be due to the antibiotic-induced lysis of bacteria caused by $\mathrm{CRO}-\mathrm{indu}-$ cing a brisk release of highly immunogenic bacterial products [65] -leading to an elevated acute inflammation $[4,66,67]$. In contrast, levels of IL- $1 \beta$ and IL-6 decreased in animals treated with adjuvant metformin, indicating its anti-inflammatory effect. The kinetic of TNF- $\alpha$ release was different, with a steady decrease in infected animals, independent of the treatment. However, the decrease was more pronounced in animals treated with adjuvant metformin $6 \mathrm{~h}$ after therapy. No significant reduction of IFN- $\gamma$ by adjuvant metformin could be detected in vivo and in vitro. For IL-10, only a trend toward reduction when treated with adjuvant metformin was found in vivo $(p=0.0591$, Fig. 3c). Our findings of reduced neuroinflammatory parameters in vitro and in vivo are in line with previously reported studies, where metformin was able to reduce neuroinflammation in different experimental neuroinflammatory diseases $[43-45,50]$.

The pathogenesis of cortical brain injury is complex and involves vasculitis in cerebral blood vessels caused by inflammation of the surrounding subarachnoid space [24, 25, 55, 68]. With adjuvant metformin therapy, a significant reduction in cortical necrosis was detected (Fig. 3f). We hypothesize that an overall reduction of inflammatory parameters (cytokines and NO) by adjuvant metformin within the first hours after treatment initiation led to an attenuation of cortical damage-a correlation previously found with other anti-inflammatory adjuvant therapies in this infant rat PM model [58, 60, 69]. Comparable CSF cytokine levels $24 \mathrm{~h}$ after treatment start between metformin-treated and untreated animals are explained by the fast decline of CSF cytokines after treatment initiation, leading to low or even undetectable levels at this time point. This is in line with previously reported clinical and experimental data [21, 58, 60, 69, 70]. Nevertheless, hippocampal apoptosis was not affected with this dose of adjuvant metformin (see Additional file 2). Notably, prevention of hippocampal apoptosis in experimental infant rat PM has so far only been repetitively described with caspase-3 inhibitors, inhibitors of matrix-metalloproteinase, and TNF- $\alpha$ converting enzyme (TACE) or modulators of neurogenesis $[55,58,71-73]$.

During the acute phase of PM, infiltration of pneumococci and leukocytes from the CSF into the basal turn of the cochlea via the cochlear aqueduct causes damage to the sensory hair cells and spiral ganglion neurons, resulting in sensorineural hearing loss $[3,33,35-37,74]$. Previous studies demonstrated the ototoxic effect of TNF- $\alpha$ in vivo and in vitro $[75,76]$, and reported a positive correlation of CSF TNF- $\alpha$ levels with increased hearing loss after PM [35]. Additionally, reactive oxygen species and NO are known mediators of blood-labyrinth barrier disruption and sensorineural hearing loss after bacterial meningitis [77-79]. A reduction of inflammatory cytokines during acute experimental PM was shown to improve subsequent hearing capacity $[60,69,80]$. In the present study, adjuvant metformin therapy significantly improved hearing capacity 5 weeks after infection (Fig. $4 a-c)$. In infected animals, metformin treatment significantly improved median click hearing thresholds compared to animals with CRO monotherapy by $40 \mathrm{~dB}$ $(60 \mathrm{~dB}$ vs. $100 \mathrm{~dB}$ in $\mathrm{CRO}$ monotherapy, $p=0.0015$, Fig. 4a). Frequency-dependent analysis showed that hearing was significantly improved by adjuvant metformin treatment in all assessed frequencies $(4,8,16$, and $32 \mathrm{kHz}$, Fig. 4b). In previous work, Perny et al. demonstrated that SGNs were affected depending on the severity of infection. The highest degree of SGN loss occurred in a basal to apical gradient, with a more pronounced hearing loss for the higher frequencies [35]. In accordance with these data, quantification of SGNs presented a significant reduction of SGNs in the basal turn of infected animals treated with CRO monotherapy, an effect that was prevented by adjuvant metformin therapy (Fig. 4d). Protection of SGNs during acute PM is crucial to maintain hearing capacity [35]. Previous studies using otoprotective compounds that attenuated the loss of SGNs were able to decrease PM-induced sensorineural hearing loss $[60,80]$. Repeated-measure ANOVA showed a significant protective effect of adjuvant metformin in infected animals over all three cochlear turns, explaining the improved hearing threshold in all assessed frequencies. Thus, we suggest that metformin also reduced the levels of ototoxic inflammatory mediators in the cochlea and protected the SGNs from PM-induced toxicity. However, a significant protection of SGNs was only demonstrated in the basal turn, representing high-frequency hearing. Therefore, there must be additional explanations for the improvement of hearing capacity at middle and low frequencies. Since metformin is known to protect auditory 
hair cells in an ototoxicity model mediated by gentamicin [48], a preservation of cochlear hair cells during PM might explain our reported improvement of pure tone hearing capacity at all measured frequencies. The protection of presynaptic ribbons of surviving hair cells would be another possible explanation for improved hearing without detectable changes in SGNs [35].

Neurogenesis describes the generation, maturation, and integration of newborn neurons into the pre-existing neuronal network [81]. It has recently been shown that metformin promotes neurogenesis and neuronal differentiation in the hippocampus and thereby improves spatial memory formation in rodents $[42,49,82]$. In this study, adjuvant metformin did not significantly increase the number of surviving $\mathrm{BrdU}^{+}$cells in the $\mathrm{NeuN}^{+}$region of the DG-neither in infected nor in mock-infected animals. A possible explanation might be the developmental stage of the hippocampus. Most studies showing significantly increased neurogenesis upon metformin treatment were performed in adult or adolescent models $[49,50,52,53,82]$. These results might therefore differ from our infant model, in which the level of endogenous neurogenesis is already considerably high. In addition, studies that showed a significant increase in neurogenesis with increased numbers of $\mathrm{BrdU}^{+}$ cells in the hippocampal DG used a higher dose of metfor$\min (200 \mathrm{mg} / \mathrm{kg})[49,82]$. In our study, we had to reduce the dose to $50 \mathrm{mg} / \mathrm{kg}$, as $200 \mathrm{mg} / \mathrm{kg}$ metformin increased mortality during acute PM (see Additional file 2). This reduced dose might have limited the neuroregenerative capacity of metformin. Many studies reported increased neurogenesis after different CNS damage like traumatic brain injury [83], stroke [84], Alzheimer's disease [85], or neonatal inflammatory pain [86]. We have previously shown in the present model that the rate of cell division in the dentate gyrus increased significantly in the first days after infection [87]. However, no statistical difference between infected and mock-infected animals was found when the survival of this pool of cells born shortly after infection was tested 5 weeks later. Nevertheless, this is in line with similar findings in a mouse model of PM showing a transient increase of neurogenesis after PM, which is not detectable anymore at 5 weeks after infection [88]-representing the time when we sacrificed our animals.

Generally, manipulation of the hippocampal neurogenic niche with the intention to induce and activate endogenous neuroregeneration after pneumococcal meningitis-induced cell death aims for compensating damage that occurred during acute infection and represents another alternative therapeutic approach to improve the outcome after pediatric pneumococcal meningitis. Therapies promoting endogenous neuronal repair by activating neural stem cells would allow a therapeutic window that could be initiated later and for longer time when compared to adjunctive anti-inflammatory substances given during acute pneumococcal meningitis. It was therefore recently argued that future research should focus increasingly on neuroregeneration [89]. However, different neurogenic substances-experimentally shown to induce neurogenesis and improve learning and memory in non-infectious models $[49,72,82]$-failed to increase neurogenesis after pneumococcal meningitis [72]. Furthermore, for other neurogenic substances like neurotrophin-3 and BDNF, it has not been investigated so far whether the improved outcomes derive from neuroprotection during acute infection or increased neuroproliferation during chronic application [71, 90-92]. Nevertheless, the combination of anti-inflammatory and neuroprotective metformin with a potent inducer of neuroregeneration (BDNF or DHF [93]) may potentially improve the chance for successful neuroregeneration after PM-induced hippocampal damage.

\section{Conclusion}

Treatment with metformin is neuro- and otoprotective in experimental pediatric PM. Metformin exerts its neuroprotective effects by reducing neuroinflammation, demonstrated by decreased CSF levels of inflammatory cytokines and reduced NO production in vitro and in vivo with subsequently reduced cortical damage. In addition, adjuvant metformin improves hearing capacity compared to standard ceftriaxone monotherapy and protected spiral ganglion neurons from PM-induced cell death. Although we could not confirm metformin's neuroregenerative properties in this study, the results identify metformin as a highly promising therapeutic option to improve the outcome of PM and other neuroinflammatory diseases.

\section{Additional files}

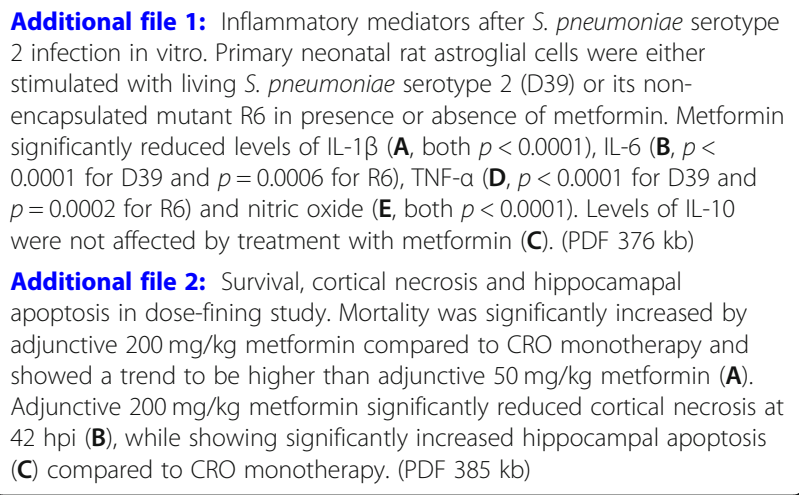

Additional file 2: Survival, cortical necrosis and hippocamapal apoptosis in dose-fining study. Mortality was significantly increased by adjunctive $200 \mathrm{mg} / \mathrm{kg}$ metformin compared to CRO monotherapy and showed a trend to be higher than adjunctive $50 \mathrm{mg} / \mathrm{kg}$ metformin (A). Adjunctive $200 \mathrm{mg} / \mathrm{kg}$ metformin significantly reduced cortical necrosis at 42 hpi (B), while showing significantly increased hippocampal apoptosis (C) compared to CRO monotherapy. (PDF $385 \mathrm{~kb}$ )

\section{Abbreviations}

ABR: Auditory brainstem response; AMPK: Adenosine monophosphateactivated protein kinase; BHI: Brain heart infusion; BrdU: Bromodeoxyuridine; CFU: Colony-forming unit; CNS: Central nervous system; CRO: Ceftriaxone; CSBA: Columbia sheep blood agar; CSF: Cerebrospinal fluid; DAPI: 4',6Diamidino-2-phenylindole; DG: Dentate gyrus; HI: Heat-inactivated; IVC: Individually ventilated cages; LPS: Lipopolysaccharide; NO: Nitric oxide; P21: Clinical S. pneumoniae strain (serotype 3); PFA: Paraformaldehyde; 
PM: Pneumococcal meningitis; PNS: Peripheral nervous system; RNS: Reactive nitrogen species; ROS: Reactive oxygen species; SGN: Spiral ganglion neurons; SPL: Sound pressure level; TACE: TNF-a converting enzyme

\section{Acknowledgements}

We thank Franziska Simon, Sabrina Hupp, Michelle Buri, and Robert Lukesch for excellent technical support. Productive discussions and inputs from the ESCMID Study Group for Infectious Diseases of the Brain (ESGIB) were highly appreciated.

\section{Funding}

This work was supported by a grant from the Swiss National Science Foundation (Grant 310030-162583).

\section{Availability of data and materials}

The datasets used and/or analyzed during the current study are available from the corresponding author on reasonable request.

\section{Authors' contributions}

$L M, N D L, D G$, and SLL conceived and designed the study. $L M, N D L$, and $J Z$ performed experiments. $L M, N D L, J Z, D G$, and SLL analyzed the data. $L M, N D L, D G$, and SLL contributed to writing of the manuscript. All authors read and approved the final manuscript. LM and NDL contributed equally to this study.

\section{Ethics approval and consent to participate}

All animal studies were approved by the Animal Care and Experimentation Committee of the Canton of Bern, Switzerland (license no. BE 129/14 and 01/18).

\section{Consent for publication}

Not applicable.

\section{Competing interests}

The authors declare that they have no competing interests.

\section{Publisher's Note}

Springer Nature remains neutral with regard to jurisdictional claims in published maps and institutional affiliations.

\section{Author details}

${ }^{1}$ Neuroinfection Laboratory, Institute for Infectious Diseases, University of Bern, Friedbühlstrasse 51, 3010 Bern, Switzerland. ${ }^{2}$ Graduate School for Cellular and Biomedical Sciences (GCB), University of Bern, Mittelstrasse 43, 3012 Bern, Switzerland.

\section{Received: 3 May 2019 Accepted: 18 July 2019}

\section{Published online: 27 July 2019}

\section{References}

1. McIntyre PB, O'Brien $\mathrm{KL}$, Greenwood B, van de Beek $\mathrm{D}$. Effect of vaccines on bacterial meningitis worldwide. Lancet. 2012;380:1703-11.

2. GBD 2016 Meningitis Collaborators JR, Kassebaum NJ, Blake N, Glennie L, Wright C, Nichols E, et al. Global, regional, and national burden of meningitis, 1990-2016: a systematic analysis for the Global Burden of Disease Study 2016. Lancet Neurol. 2018;17:1061-82.

3. Edmond K, Clark A, Korczak VS, Sanderson C, Griffiths UK, Rudan I. Global and regional risk of disabling sequelae from bacterial meningitis: a systematic review and meta-analysis. Lancet Infect Dis. 2010;10:317-28.

4. Mook-Kanamori BB, Geldhoff M, van der Poll T, van de Beek D. Pathogenesis and pathophysiology of pneumococcal meningitis. Clin Microbiol Rev. 2011; 24:557-91.

5. Lucas MJ, Brouwer MC, van de Beek D. Neurological sequelae of bacterial meningitis. J Inf Secur. 2016;73:18-27.

6. Iovino F, Engelen-Lee J-Y, Brouwer M, van de Beek D, van der Ende A, Valls Seron $\mathrm{M}$, et al. plgR and PECAM-1 bind to pneumococcal adhesins RrgA and PspC mediating bacterial brain invasion. J Exp Med. 2017;214:1619-30.

7. Cundell DR, Gerard NP, Gerard C, Idanpaan-Heikkila I, Tuomanen El. Streptococcus pneumoniae anchor to activated human cells by the receptor for platelet-activating factor. Nature. 1995;377:435-8.
8. Ring A, Weiser JN, Tuomanen El. Pneumococcal trafficking across the blood-brain barrier molecular analysis of a novel bidirectional pathway; 1998

9. Zhang JR, Mostov KE, Lamm ME, Nanno M, Shimida S, Ohwaki M, et al. The polymeric immunoglobulin receptor translocates pneumococci across human nasopharyngeal epithelial cells. Cell. 2000; 102:827-37

10. Iovino F, Molema G, Bijlsma JJE. Platelet endothelial cell adhesion molecule-1, a putative receptor for the adhesion of Streptococcus pneumoniae to the vascular endothelium of the blood-brain barrier. Infect Immun. 2014:82:3555-66.

11. Iovino F, Molema G, Bijlsma JJE. Streptococcus pneumoniae interacts with plgR expressed by the brain microvascular endothelium but does not colocalize with PAF receptor. PLoS One. 2014;9:e97914.

12. Doran KS, Fulde M, Gratz N, Kim BJ, Nau R, Prasadarao N, et al. Hostpathogen interactions in bacterial meningitis. Acta Neuropathol. 2016; 131:185-209.

13. Zysk G, Schneider-Wald BK, Hyuk Hwang J, Bejo L, Sik Kim K, Mitchell $\mathrm{TJ}$, et al. Pneumolysin is the main inducer of cytotoxicity to brain microvascular endothelial cells caused by Streptococcus pneumoniae. Infect Immun. 2001:69:845-52.

14. Mahdi LK, Wang H, Van der Hoek MB, Paton JC, Ogunniyi AD. Identification of a novel pneumococcal vaccine antigen preferentially expressed during meningitis in mice. J Clin Invest. 2012;122:2208-20.

15. Iliev Al, Stringaris AK, Nau R, Neumann H. Neuronal injury mediated via stimulation of microglial toll-like receptor-9 (TLR9). FASEB J. 2003; 18:412-4.

16. Marques CP, Cheeran MC-J, Palmquist JM, Hu S, Lokensgard JR. Microglia are the major cellular source of inducible nitric oxide synthase during experimental herpes encephalitis. J Neuro-Oncol. 2008;14:229-38.

17. Mitchell L, Smith SH, Braun JS, Herzog K, Weber JR, Tuomanen El. Dual phases of apoptosis in pneumococcal meningitis. J Infect Dis. 2004;190: 2039-46.

18. Agyeman P, Grandgirard D, Leib SL. Chapter 23: Pathogenesis and pathophysiology of bacterial infections. In: Scheld MW, Marra CM, Whitley RJ, editors. Philadelphia: Infections of the Central Nervous System: Lippincott Williams \& Wilkins; 2014. pp 341-64.

19. van Furth AM, Roord JJ, van Furth $R$. Roles of proinflammatory and antiinflammatory cytokines in pathophysiology of bacterial meningitis and effect of adjunctive therapy. Infect Immun. 1996;64:4883-90.

20. Waage A, Halstensen A, Shalaby R, Brandtzaeg P, Kierulf P, Espevik T. Local production of tumor necrosis factor alpha, interleukin 1, and interleukin 6 in meningococcal meningitis. Relation to the inflammatory response. J Exp Med. 1989;170:1859-67.

21. Sharief MK, Ciardi M, Thompson EJ. Blood-brain barrier damage in patients with bacterial meningitis: association with tumor necrosis factor-alpha but not interleukin-1 beta. J Infect Dis. 1992;166:350-8.

22. van de Beek D, de Gans J, Tunkel AR, Wijdicks EFM. Community-Acquired Bacterial Meningitis in Adults. N Engl J Med. 2006:354:44-53.

23. Hoffman O, Weber JR. Pathophysiology and treatment of bacterial meningitis. Ther Adv Neurol Disord. 2009:2:401-12.

24. Leib SL, Kim YS, Chow LL, Sheldon RA, Täuber MG. Reactive oxygen intermediates contribute to necrotic and apoptotic neuronal injury in an infant Rat model of bacterial meningitis due to group b Streptococci; 1996.

25. Nau R, Brück W. Neuronal injury in bacterial meningitis: mechanisms and implications for therapy. Trends Neurosci. 2002;25:38-45.

26. Nau R, Soto A, Bruck W. Apoptosis of neurons in the dentate gyrus in humans suffering from bacterial meningitis. J Neuropathol Exp Neurol. 1999; 58:265-74.

27. Grandgirard D, Bifrare Y-D, Pleasure SJ, Kummer J, Leib SL, Täuber MG Pneumococcal meningitis induces apoptosis in recently postmitotic immature neurons in the dentate gyrus of neonatal rats. Dev Neurosci. 2007:29:134-42.

28. Bifrare Y-D, Gianinazzi C, Imboden H, Leib SL, Täuber MG. Bacterial meningitis causes two distinct forms of cellular damage in the hippocampal dentate gyrus in infant rats. Hippocampus. 2003;13:481-8.

29. Leib SL, Kim YS, Chow LL, Sheldon RA, Täuber MG. Reactive oxygen intermediates contribute to necrotic and apoptotic neuronal injury in an infant rat model of bacterial meningitis due to group B streptococci. J Clin Invest. 1996;98:2632-9. 
30. Wellmer A, Noeske C, Gerber J, Munzel U, Nau R. Spatial memory and learning deficits after experimental pneumococcal meningitis in mice. Neurosci Lett. 2000;296:137-40.

31. Loeffler JM, Ringer R, Hablützel M, Täuber MG, Leib SL. The free radical scavenger a-phenyl-tert-butyl Nitrone aggravates hippocampal apoptosis and learning deficits in experimental pneumococcal meningitis. J Infect Dis. 2001;183:247-52

32. Leib SL, Heimgartner C, Bifrare Y-D, Loeffler JM, Täuber MG. Dexamethasone aggravates hippocampal apoptosis and learning deficiency in pneumococcal meningitis in infant rats. Pediatr Res. 2003;54:353-7.

33. Møller MN, Brandt C, Østergaard C, Caye-Thomasen P. Bacterial invasion of the inner ear in association with pneumococcal meningitis. Otol Neurotol. 2014;35:e178-86.

34. Klein M, Koedel U, Pfister H-W, Kastenbauer S. Morphological correlates of acute and permanent hearing loss during experimental pneumococcal meningitis. Brain Pathol. 2003;13:123-32.

35. Perny $M$, Roccio M, Grandgirard D, Solyga M, Senn P, Leib SL. The severity of infection determines the localization of damage and extent of sensorineural hearing loss in experimental pneumococcal meningitis. $J$ Neurosci. 2016;36:7740-9

36. van de Beek D, de Gans J, Spanjaard L, Weisfelt M, Reitsma JB, Vermeulen M. Clinical features and prognostic factors in adults with bacterial meningitis. N Engl J Med. 2004;351:1849-59.

37. Chandran A, Herbert $H$, Misurski D, Santosham M. Long-term sequelae of childhood bacterial meningitis: an underappreciated problem. Pediatr Infect Dis J. 2011;30:3-6.

38. Brouwer MC, McIntyre P, Prasad K, van de Beek D. Corticosteroids for acute bacterial meningitis. In: van de Beek $D$, editor. Cochrane Database of Systematic Reviews. Chichester: Wiley; 2015. p. CD004405.

39. van de Beek D, Cabellos C, Dzupova O, Esposito S, Klein M, Kloek AT, et al. ESCMID guideline: diagnosis and treatment of acute bacterial meningitis Clin Microbiol Infect. 2016;22:S37-62.

40. Bally L, Grandgirard D, Leib SL. Inhibition of hippocampal regeneration by adjuvant dexamethasone in experimental infant rat pneumococcal meningitis. Antimicrob Agents Chemother. 2016;60:1841-6.

41. Martin-Montalvo A, Mercken EM, Mitchell SJ, Palacios HH, Mote PL, Scheibye-Knudsen $M$, et al. Metformin improves healthspan and lifespan in mice HHS public access. Nat Commun. 2013;4:2192.

42. Potts MB, Lim DA. An old drug for new ideas: metformin promotes adult neurogenesis and spatial memory formation. Cell Stem Cell. 2012;11:5-6.

43. Pan $Y$, Sun $X$, Jiang $L, H u L$, Kong $H$, Han $Y$, et al. Metformin reduces morphine tolerance by inhibiting microglial-mediated neuroinflammation. J Neuroinflammation. 2016;13 https://doi.org/10.1186/s12974-016-0754-9.

44. Nath N, Khan M, Paintlia MK, Hoda N, Giri S. Metformin attenuated the autoimmune disease of the central nervous system in animal models of multiple sclerosis $1 \mathrm{NIH}$ public access. J Immunol. 2009;182:8005-14.

45. Oliveira WH, Nunes AK, França MER, Santos LA, Lós DB, Rocha SW, et al. Effects of metformin on inflammation and short-term memory in streptozotocin-induced diabetic mice. Brain Res. 2016;1644:149-60.

46. Patil SP, Jain PD, Ghumatkar PJ, Tambe R, Sathaye S. Neuroprotective effec of metformin in MPTP-induced Parkinson's disease in mice. Neuroscience. 2014;277:747-54.

47. Ge X-H, Zhu G-J, Geng D-Q, Zhang H-Z, He J-M, Guo A-Z, et al. Metformin protects the brain against ischemia/reperfusion injury through PI3K/Akt1/ JNK3 signaling pathways in rats. Physiol Behav. 2017;170:115-23.

48. Glutz A, Leitmeyer K, Setz C, Brand Y, Bodmer D. Metformin protects auditory hair cells from gentamicin-induced toxicity in vitro. Audiol Neurotol. 2015;20:360-9.

49. Wang J, Gallagher D, DeVito LM, Cancino Gl, Tsui D, He L, et al. Metformin activates an atypical PKC-CBP pathway to promote neurogenesis and enhance spatial memory formation. Cell Stem Cell. 2012;11:23-35.

50. Jin Q, Cheng J, Liu Y, Wu J, Wang $X$, Wei S, et al. Improvement of functional recovery by chronic metformin treatment is associated with enhanced alternative activation of microglia/macrophages and increased angiogenesis and neurogenesis following experimental stroke. Brain Behav Immun. 2014;40:131-42.

51. Qi B, Hu L, Zhu L, Shang L, Sheng L, Wang X, et al. Metformin attenuates cognitive impairments in hypoxia-ischemia neonatal rats via improving remyelination. Cell Mol Neurobiol. https://doi.org/10.1 007/s10571-016-0459-8. Published Online First: 29 December 2016
52. Liu Y, Tang G, Zhang Z, Wang Y, Yang G-Y. Metformin promotes focal angiogenesis and neurogenesis in mice following middle cerebral artery occlusion. Neurosci Lett. 2014;579:46-51.

53. Dadwal $P$, Mahmud N, Sinai L, Azimi A, Fatt M, Wondisford FE, et al. Activating endogenous neural precursor cells using metformin leads to neural repair and functional recovery in a model of childhood brain injury. Stem Cell Rep. 2015;5:166-73.

54. Muri L, Perny M, Zemp J, Grandgirard D, Leib SL. Combining ceftriaxone with doxycycline and daptomycin reduces mortality, neuroinflammation, brain damage and hearing loss in infant rat pneumococcal meningitis. Antimicrob Agents Chemother. https://doi. org/10.1128/AAC.00220-19. Published Online First: 6 May 2019

55. Leib SL, Clements JM, Lindberg RLP, Heimgartner C, Loeffler JM, Pfister L-A, et al. Inhibition of matrix metalloproteinases and tumour necrosis factor a converting enzyme as adjuvant therapy in pneumococcal meningitis. Brain. 2001;124:1734-42.

56. Grandgirard D, Steiner O, Täuber MG, Leib SL. An infant mouse model of brain damage in pneumococcal meningitis. Acta Neuropathol. 2007:114:609-17.

57. Spreer A, Gerber J, Hanssen M, Schindler S, Hermann C, Lange P, et al. Dexamethasone increases hippocampal neuronal apoptosis in a rabbit model of Escherichia coli meningitis. Pediatr Res. 2006;60:210-5.

58. Liechti FD, Grandgirard D, Leppert D, Leib SL. Matrix metalloproteinase inhibition lowers mortality and brain injury in experimental pneumococcal meningitis. Infect Immun. 2014;82:1710-8.

59. Gerber J, Pohl K, Sander V, Bunkowski S, Nau R. Rifampin followed by ceftriaxone for experimental meningitis decreases lipoteichoic acid concentrations in cerebrospinal fluid and reduces neuronal damage in comparison to ceftriaxone alone. Antimicrob Agents Chemother. 2003; 47:1313-7.

60. Muri L, Grandgirard D, Buri M, Perny M, Leib SL. Combined effect of non-bacteriolytic antibiotic and inhibition of matrix metalloproteinases prevents brain injury and preserves learning, memory and hearing function in experimental paediatric pneumococcal meningitis. J Neuroinflammation. 2018;15:233.

61. Coimbra RS, Loquet G, Leib SL. Limited efficacy of adjuvant therapy with dexamethasone in preventing hearing loss due to experimental pneumococcal meningitis in the infant rat. Pediatr Res. 2007;62:291-4.

62. Steinfort C, Wilson R, Mitchell T, Feldman C, Rutman A, Todd H, et al. Effect of Streptococcus pneumoniae on human respiratory epithelium in vitro. Infect Immun. 1989;57:2006-13.

63. Thäle C, Kiderlen AF. Sources of interferon-gamma (IFN- - ) in early immune response to listeria monocytogenes. Immunobiology. 2005; 210:673-83.

64. Seifarth C, Schehler B, Schneider $H$. Effectiveness of metformin on weight loss in non-diabetic individuals with obesity. Exp Clin Endocrinol Diabetes. 2012:121:27-31.

65. Tuomanen $\mathrm{E}$, Liu H, Hengstler B, Zak O, Tomasz A. The induction of meningeal inflammation by components of the pneumococcal cell wall. J Infect Dis. 1985;151:859-68.

66. Nau R, Eiffert $H$. Minimizing the release of proinflammatory and toxic bacterial products within the host: a promising approach to improve outcome in life-threatening infections. FEMS Immunol Med Microbiol. 2005:44:1-16.

67. Nau R, Eiffert H. Modulation of release of proinflammatory bacterial compounds by antibacterials: potential impact on course of inflammation and outcome in sepsis and meningitis. Clin Microbiol Rev. 2002;15:95-110

68. Koedel U, Scheld WM, Pfister H-W. Pathogenesis and pathophysiology of pneumococcal meningitis. Lancet Infect Dis. 2002;2:721-36.

69. Grandgirard D, Burri M, Agyeman P, Leib SL. Adjunctive daptomycin attenuates brain damage and hearing loss more efficiently than rifampin in infant rat pneumococcal meningitis. Antimicrob Agents Chemother. 2012; 56:4289-95

70. Grandgirard D, Oberson K, Bühlmann A, Gäumann R, Leib SL. Attenuation of cerebrospinal fluid inflammation by the nonbacteriolytic antibiotic daptomycin versus that by ceftriaxone in experimental pneumococcal meningitis. Antimicrob Agents Chemother. 2010:54:1323-6.

71. Bifrare Y-D, Kummer J, Joss P, Täuber MG, Leib SL. Brain-derived neurotrophic factor protects against multiple forms of brain injury in bacterial meningitis. J Infect Dis. 2005;191:40-5. 
72. Liechti FD, Studle N, Theurillat R, Grandgirard D, Thormann W, Leib SL. The mood-stabilizer lithium prevents hippocampal apoptosis and improves spatial memory in experimental meningitis. PLoS One. 2014;9:17-9.

73. Gianinazzi C, Grandgirard D, Imboden H, Egger L, Meli DN, Bifrare Y-D, et al. Caspase-3 mediates hippocampal apoptosis in pneumococcal meningitis. Acta Neuropathol. 2003;105:499-507.

74. Klein M, Koedel U, Pfister H-W, Kastenbauer S. Meningitis-associated hearing loss: protection by adjunctive antioxidant therapy. Ann Neurol. 2003;54:451-8.

75. Wu Q, Wang G-P, Xie J, Guo J-Y, Gong S-S. Tumor necrosis factor-a-induced ototoxicity in mouse cochlear organotypic culture. PLoS One. 2015;10: e0127703.

76. Aminpour S, Tinling SP, Brodie HA. Role of tumor necrosis factor-alpha in sensorineural hearing loss after bacterial meningitis. Otol Neurotol. 2005;26:602-9.

77. Kastenbauer S, Klein M, Koedel U, Pfister HW. Reactive nitrogen species contribute to blood-labyrinth barrier disruption in suppurative labyrinthitis complicating experimental pneumococcal meningitis in the rat. Brain Res. 2001;904:208-17.

78. Amaee FR, Comis SD, Osborne MP, Drew S, Tarlow MJ. Possible involvement of nitric oxide in the sensorineural hearing loss of bacterial meningitis. Acta Otolaryngol. 1997:117:329-36

79. Klein M, Koedel U, Kastenbauer S, Pfister H-W. Nitrogen and oxygen molecules in meningitis-associated Labyrinthitis and hearing impairment. Infection. 2008;36:2-14.

80. Meli DN, Coimbra RS, Erhart DG, Loquet G, Bellac CL, Täuber MG, et al. Doxycycline reduces mortality and injury to the brain and cochlea in experimental pneumococcal meningitis. Infect Immun. 2006;74:3890-6.

81. Seib DRM, Martin-Villalba A. Neurogenesis in the normal ageing hippocampus: a mini-review. Gerontology. 2015;61:327-35.

82. Fatt M, Hsu K, He L, Wondisford F, Miller FD, Kaplan DR, et al. Metformin acts on two different molecular pathways to enhance adult neural precursor proliferation/self-renewal and differentiation. Stem Cell Rep. 2015;5:988-95

83. Zheng W, ZhuGe Q, Zhong M, Chen G, Shao B, Wang $H$, et al. Neurogenesis in adult human brain after traumatic brain injury. $J$ Neurotrauma. 2013:30:1872-80.

84. Jin K, Wang X, Xie L, Mao XO, Zhu W, Wang Y, et al. Evidence for stroke-induced neurogenesis in the human brain. Proc Natl Acad Sci U S A. 2006;103:13198-202.

85. Jin K, Galvan V, Xie L, Mao XO, Gorostiza OF, Bredesen DE, et al. Enhanced neurogenesis in Alzheimer's disease transgenic (PDGF-APPSW,Ind) mice. Proc Natl Acad Sci U S A. 2004;101:13363-7.

86. Leslie ATFS, Akers KG, Martinez-Canabal A, de Mello LEA, Covolan L, Guinsburg R. Neonatal inflammatory pain increases hippocampal neurogenesis in rat pups. Neurosci Lett. 2011;501:78-82.

87. Wittwer M, Grandgirard D, Rohrbach J, Leib SL. Tracking the transcriptional host response from the acute to the regenerative phase of experimental pneumococcal meningitis. BMC Infect Dis. 2010;10:176.

88. Hoffmann O, Mahrhofer C, Rueter N, Freyer D, Bert B, Fink H, et al. Pneumococcal cell wall-induced meningitis impairs adult hippocampal neurogenesis. Infect Immun. 2007;75:4289-97.

89. Liechti FD, Grandgirard D, Leib SL. Bacterial meningitis: insights into pathogenesis and evaluation of new treatment options: a perspective from experimental studies. Future Microbiol. 2015;10:1195-213.

90. Xu D, Lian D, Wu J, Liu Y, Zhu M, Sun J, et al. Brain-derived neurotrophic factor reduces inflammation and hippocampal apoptosis in experimental Streptococcus pneumoniae meningitis. J Neuroinflammation. 2017;14:156.

91. Li L, Shui Q-X, Li X. Neuroprotective effects of brain-derived neurotrophic factor (BDNF) on hearing in experimental pneumococcal meningitis. J Child Neurol. 2005:20:51-6.

92. Lian D, He D, Wu J, Liu Y, Zhu M, Sun J, et al. Exogenous BDNF increases neurogenesis in the hippocampus in experimental Streptococcus pneumoniae meningitis. J Neuroimmunol. 2016;294:46-55.

93. Wurzelmann M, Romeika J, Sun D. Therapeutic potential of brain-derived neurotrophic factor (BDNF) and a small molecular mimics of BDNF for traumatic brain injury. Neural Regen Res. 2017;12:7.

\section{Ready to submit your research? Choose BMC and benefit from:}

- fast, convenient online submission

- thorough peer review by experienced researchers in your field

- rapid publication on acceptance

- support for research data, including large and complex data types

- gold Open Access which fosters wider collaboration and increased citations

- maximum visibility for your research: over $100 \mathrm{M}$ website views per year

At BMC, research is always in progress.

Learn more biomedcentral.com/submissions 